\title{
The Relationships Between Personal Resilience and Leadership Practices Of School Principals In Jordan
}

\author{
Aieman Ahmad Al-Omari \\ The Hashemite University, Jordan
}

\begin{abstract}
The study aimed to investigate the relationships between personal resilience and leadership practices of school principals in Jordan. The sample consisted 800 teachers chosen randomly from Zarqa governorate schools. Two questionnaires: The Personal Resilience Questionnaire, and Leadership Practices Inventory (Observer) were used in this study. Results showed that regarding to LPI the mean of encouraging the heart is higher than all other means, followed by enabling others to act, challenging the process, modeling the way, and inspiring a shared vision. With regard to the seven dimensions of the PRQ Scale, the mean of organized is higher than all other means, followed by flexible: social, flexible: thoughts, proactive, focused, positive: the world, and positive: yourself. Statistically significant, positive relationships were observed among: Positive: The World with challenging the process, inspiring a shared vision, enabling others to act, modeling the Way, and encouraging the heart. Positive: Yourself with challenging the process. Focused with challenging the process, and inspiring a shared vision. Flexible: Thoughts with challenging the process, and inspiring a shared vision. Organized with inspiring a shared vision, and modeling the way. There were no significant differences between BSc. and Graduate teachers in all dimensions of LPI. There were significant differences in LPI overall, the differences were for BSc., there is no difference in teachers perceived the principals personal resilience related to their gender, education, and teaching experience.
\end{abstract}

Key words: Personal resilience, leadership practice, school principals, Jordan

\section{INTRODUCTION}

The principal of tomorrow's schools must be a school leader, one who possesses the requisite skills, capacities, and commitment to deal with increased responsibilities and to lead the accountability parade. Without good leadership, the chances for systemic improvement in teaching and learning are not good. A commitment to effective leadership would help principals adapt significantly to the changing circumstances (Tirozzi, 2001).

Over the years, considerable efforts have been made to identify specific responsibilities of the school principal. Among the most important responsibilities are the development of a vision and motivation of faculty and staff toward achievement of student success (Cunningham \& Cordeiro, 2000). Kouzes \& Posner (2002) stated that leadership consists of a set of skills and practices that enable them to get extraordinary things done, even though in rough or laborious times. Leaders should be prepared to take considerable risks to achieve their mission. Webster (2000) emphasized that leaders should have high expectations and standards for themselves and their followers at all times. Greenfield (1995) argued that an effective administration is not possible without efficient and effective leadership, and if school leadership is to be successful, it must deal with the five demands: moral, social, instructional, managerial, and political. Leadership is about motivating other people. But to motivate others, leaders should have certain leadership qualities or characteristics. 
Cunningham \& Cordeiro (2000) believe that the leader needs to be prepared to deal with the inevitable social, cultural, economic, technological, bureaucratic, and political obstacles that can block improvements efforts, which have a significant impact on all aspects of the school itself; the leadership, curriculum, school organization, faculty, student behavior, community relations, and the learning-teaching process. Therefore, principals must be more than administrators; they must facilitate change in the school by structuring challenges with reasonable risk to improve their leadership and management skills and the school's progress (Osburn, 1993).

Kouzes \& Posner (2002) found that leaders demonstrated certain practices when they perform at their best, by demonstrating these practices, the leader transforms values into actions, visions into realities, obstacles into innovations, and risks into rewards. Bolman \& Deal (1997) said that leaders are not independent actors in the organization but are shaped by their constituents, leadership is not a matter of what a leader does but also of what occurs in a relationship. Also, Du Brain (1998) supported that by stating that leadership is in fact a partnership. Senge, Cambron-McCabe, Lucas, Smith, Dutton, \& Kleiner (2000) stated that the leader must be willing to take a stand for the guiding ideas he or she considered as important for the organization, while remaining open and flexible to the viewpoints of others.

The operationalization of the construct of leadership for this research is based on conceptualization of the Kouzes and Posner leadership model. These practices are: Model the Way, Inspire a Shared Vision, Challenge the Process, Enable Others to Act, and Encourage the Heart. They developed a model of leadership after analyzing the personal best cases, and subsequently developed The Leadership Practices Inventory (LPI) to enable them to measure the leadership behaviors, actions and performance uncovered during their research. They concluded that the leadership process enables ordinary managers to exhibit the best from themselves and others (Kouzes \& Posner, 1987, 1995, 2002).

In their studies, Kouzes and Posner, their findings are discussed below:

a) Challenging the Process: Leadership is an active process. To lead others to greatness, leaders seek opportunities to change the status quo or to make a paradigm shift. If leaders would like to change the status quo, they should look for innovation to improve the organization, take risks, accept responsibility, and be accountable for their actions. These leaders seek and accept challenging opportunities to test their abilities (Kouzes \& Posner, 1987, 1995, 2002).

By either creating new ideas or recognizing and supporting new ideas, leaders show willingness to challenge the system in order to turn these ideas into actions and to get new products, processes, and services adopted. In order to succeed, leaders must be prepared to make mistakes because every false step opens the door to a new opportunity. Instead of punishing failure, they encourage it. They learn from their mistakes rather than shift the blame on someone else. Therefore, leaders must create opportunities for people to solve problems, make discoveries, explore new ground, and figure out how to deal with an external threat. It is imperative that leaders know the skills and capabilities of their people. The leader should not be the only one being challenged, but everyone should be exposed to challenges within their capabilities to perform. By participating in challenging opportunities, people often bring forth skills and abilities that were otherwise being oblivious (Kouzes \& Posner, 1987, 1995, 2002).

b) Inspiring a Shared Vision: Effective leaders passionately believe that they can make a difference by envisioning the future and creating an ideal and unique image of what the organization can become. Through their magnetism, persuasion and inspiration they enlist others in their dreams. A vision is portrayed by an ideal and unique image of a 
common future. A vision is only effective when the leader has the ability to communicate that vision so that others could see what the leader wants them to see. The image that followers develop in their minds is highly dependent upon the leader's description of that specific image (Kouzes \& Posner, 1987, 1995, 2002).

c) Enabling Others to Act: Leaders foster collaboration and build cooperative relationships with colleagues, they actively involve others in planning and give them freedom of choice in the decision-making. They strengthen others and help each person feel capable and powerful. The leader and employees must collaborate in order to develop employee commitment and skills, solve problems, and be responsive to environmental pressures. Trust is essential for building collaborative relationships between employees. When a leader is viewed as helpful and perceptive, other people will more likely be committed to the leader and the organization's goals (Kouzes \& Posner, 1987, 1995, 2002).

d) Modeling the Way: Leaders need to have a set of high standards by which the organization is measured, a set of principles concerning the way people should be treated and the way goals should be pursued that make the organization unique and distinctive. They create a program of excellence and then set the example for others to follow (Kouzes \& Posner, 1987, 1995, 2002).

e) Encouraging the Heart: Leaders give recognition to those contributing to the success of the project and encourage staff members by celebrating team accomplishment regularly. By recognizing such accomplishments, leaders let others know what they mean to the organization. Successful leaders have high expectations for themselves and their employees. Leaders should come up with different kinds of rewards and not only rely on formal rewards. Instead, leaders can make tremendous use of intrinsic rewards, such as certificates, plaques, and other tangible gifts (Kouzes \& Posner, 1987, 1995, 2002).

Kouzes \& Posner (1993) developed their instrument, the (LPI), through a triangulation of qualitative and quantitative research methods and studies. Through in-depth interviews and written case studies from people's personal-best leadership experiences, they generated the five leadership practices: challenging the process, inspiring a shared vision, enabling others to act, modeling the way, and encouraging the heart.

The LPI empirically measures the leadership actions and behaviors based on the five leadership practices. The LPI contains thirty statements, six statements will be used to measure each of these leadership practices using a five point-Likert scale. These statements describe each of the various leadership actions and behaviors.

The findings of Abu-Tineh, Khasawneh, \& Al-Omari (2008) indicated that Kouzes and Posner's model is being moderately practiced by Jordanian school principals. Female teachers and basic school teachers' more than male teachers and high school teachers' identified their principals as transformational. Finally, there were no significant differences among the three experience level groups of teachers in their perceptions of each dimension of Kouzes and Posner's Model.

Furthermore, principals should also demonstrate high levels of educational leadership to address complex and changing tasks (Whitaker \& Turner, 2000). In order to respond creatively, flexibly and quickly to the changing realities of life outside the school, the principal requires certain skills to deal with their circumstances, oversee change and improve student achievement. Garmezy \& Masten (1996) maintained that to master change successfully a leader requires psychological and biological strengths, which are called resilience. 
Definitions of resilience came from different views; psychology Resilience is the ability to bounce back: to withstand hardship and repair yourself (Wolin \& Wolin, 1993; Higgins, 1994). Psychiatry Resilience is the psychological and biological strengths humans require to master change successfully (Flach, 1988) Developmental Psychopathology Resilience is the ability to cope with challenges and threats, while maintaining an internal, and integrated sense of self (Garmezy \& Masten, 1996). Human Development Resilience is the ability to withstand or successfully cope with adversity (Werner \& Smith, 2001). Change Management Resilience is the ability to demonstrate both strength and flexibility during the change process, while displaying minimal dysfunctional behavior (Conner, 1993). Nursing Resilience is the ability to develop regenerate power to respond to the internal or external environment for survival, growth or development (Jones, 1991). Social Sciences Resilience is the ability to bounce back from negative life experiences and become stronger while overcoming them (Henderson \& Milstein, 1996). Medicine Resilience is the ability to recognize pain, acknowledge its purpose, and tolerate it for a while until things begin to normalize (Flach, 1988).

Sagor (1996) concurred by stating that resilience is a set of attributes that provide people with the strength and courage to confront the overwhelming obstacles they are bound to face in life. When individuals are judged to be resilient, the implication is that they have displayed adaptive behaviors despite facing risks and adversaries (Wang \& Gordon, 1994).

Drawing from the research on resilience, five characteristics emerge that would help school administrators to move ahead in the face of adversity (Patterson, 2001; Hagevik, 1998; Conner,1993; Benard, 1993; Higgins, 1994; Henderson \& Milstein, 1996; Flach, 1988).

- Proactive: Resilient people take a proactive approach rather than a reactive or passive approach to problem solving (Conner, 1993). They are usually self reliant and independent while at the same time socially skillful to solicit help when needed (Henderson \& Milstein, 1996; Wolin \& Wolin, 1993). Flach (1988) characterized resilient people as independent in their thoughts and actions, and have the skills to set proper limits on their dependency.

- Positive: Resilient people see major changes or disruptions as uncomfortable but opportunities to grow and develop (Hagevik, 1998; Conner, 1993; Patterson, 2001). Although they believe they can learn from their negative experiences and challenges to deal effectively with difficult situations (Conner, 1992; Patterson, 2001). According to Benard (1993), resilient people generative positive responses from other people, while Henderson \& Milstein (1996) see resilient people as those who have a positive view of the future.

- Focused: Resilient people are focused, committed to life, and maintain a clear vision to purposefully achieve their objectives (Conner, 1993; Flach, 1988; Hagevik, 1998). Patterson (2001) views resilient school leaders as those who consistently and persistently apply strategies to operate from a clear set of personal and organizational values, despite any external adversities.

- Flexible: Resilient people have the capacity to believe that change is a manageable process. School principals who have high levels of flexibility have a high tolerance for ambiguity, and need only a short time to recover from adversity (Hagevik, 1998; Conner, 1993; Patterson, 2001; Wolin \& Wolin, 1993; Benard, 1993; Henderson \& Milstein, 1996; Flach, 1988).

- Organized: Resilient people have the ability to quickly sort information, build structures in the midst of chaos, plan actions for efficient use of resources, and avoid acting on impulses (Conner, 1993; Hagevik, 1998; Benard, 1993). 
Conner's model appears to describe the most comprehensive sense of the dimensions of resilience. According to Conner (1993), leadership dimensions of administrators include the areas of perception, thinking, and behavior and appear to be related to the concept of resilience and how people deal with changing circumstances and a changing world. Patterson (2001) stated that school leaders should see change as a challenge by accepting their responsibilities and move ahead in the face of adversity, because by accepting responsibilities they become more resilient. In addition, school principals have a challenge to provide good leadership to schools to achieve their mission, vision and goals in the face of adverse conditions and imposed changes.

Conner and his associates at ODR (Organizational Development Resources) developed an instrument, the Personal Resilience Questionnaire (PRQ) in 1990. The final version of the PRQ contains 70 items that measure the five (seven including sub - characteristics) general characteristics that are related to resilience, namely: (a) Positive: ("The World") and ("Yourself"), (b) Focused, (c) Flexible: ("Thoughts") and ("Social"), (d) Organized. (e) Proactive which is used in this research:

Positive (the World), designed to assess the tendency to see opportunities in a variety of situations. It should correlate positively with measures of positive affectivity, optimistic attribution style, and related measures (such as life satisfaction), and it should correlate negatively with measures of negative affectivity and related measures.

Positive (yourself), designed to assess a person's general sense of self-efficacy in responding to situations. It should correlate positively with measures of internal locus of control, self-esteem, and self-efficacy.

Focused, designed to assess a person's clarity of purpose; that is, the extent to which the person has a sense of direction in his or her life. There are few well defined constructs that would be expected to correspond directly, but it should correlate with measures of meaning or purpose in life.

Flexible (thoughts), designed to assess the extent to which a person tends to be comfortable with ambiguity, to entertain unfamiliar or contradictory working with complex ideas. It should correlate positively with measures of ambiguity tolerance, creativity, and cognitive complexity.

Flexible (social), designed to assess the extent to which a person gives and receives social support; that is, the interdependence that they recognize and have established with those around them, it should correlate positively with measures of social support and extroversion, and negatively with measures of alienation.

Organized, designed to assess the extent to which a person can impose structure on ambiguous situations, including the ability to systematize, sequence, and plan. There are few well-defined constructs that would be expected to correspond directly.

Proactive, designed to assess the extent to which a person is willing to act on his or her environment in the face of uncertainty or risk. It should correlate positively with measures of action tendencies and risk tolerance.

Limited research has been done to assess the relationships among principals' personal resilience and their leadership practices as perceived their teachers in Jordan. This study specifically examined the comparisons between teachers' gender, education, and teaching experience.

\section{PROBLEM OF THE STUDY AND RESEARCH QUESTIONS}

The purpose of this investigation was to determine relationships among principals' personal resilience and their leadership practices as perceived their teachers in Zarqa governorate. Conner's (1992) research over the years defined seven general dimension of resilience: 
Positive (Yourself), Positive (The World), Focused, Flexible (Thoughts), Flexible (Social), Organized, and Proactive. The Personal Resilience Questionnaire (PRQ) was developed to assess individuals on the seven dimensions of resilience. The instrument was applied in this investigation to high school principals.

A second part of the investigation Kouzes \& Posner (1987,1993) designed the (LPI) questionnaire to measure leadership actions and behaviors based on the five leadership practices: challenging the process, inspiring a shared vision, enabling others to act, modeling the way, and encouraging the heart.

The investigation attempted to answer the research questions below

Q1: How do teachers at Zarqa Governorate perceive their principals leadership practice?

Q2: How do teachers at Zarqa Governorate perceive their principals personal resilience?

Q3: Are there significant relationships among principals' personal resilience and their leadership practices as perceived their teachers?

Q4: Do principals leadership practice differ based on teachers gender, education, and teaching experience?

Q5: Do principals personal resilience differ based on teachers gender, education, and teaching experience?

\section{SIGNIFICANCE OF THE STUDY}

Tirozzi (2001) contends that a commitment to leadership would help principals adapt significantly to the changing circumstances. Hence, this investigation should add information to the scholarly research and literature in the field of school leadership. Calls for school reform and restructuring, in Jordan have emphasized the importance of effective school leaders. Kouzes and Posner's Leadership Model and Personal Resilience provides school principals with practical guidance on how to lead. The results of this investigation, therefore, served as a basis for school principals to assess their leadership strengths and weaknesses, and used the findings to become more effective school leaders and dealing with changes. Furthermore, it is hoped that this research will be seen as a starting point for research in Kouzes and Posner's Leadership Model and Conner's Resilience model in Jordanian schools and stimuli for further research to provide valuable insight for both academics and practitioners. To date there is no reported study identifying the relationships among principals' personal resilience and their leadership practices in Jordan.

\section{Research Design}

\section{METHODOLOGY}

This quantitative investigation employed the survey method as its research design.

\section{The Population and Sample of the Study}

The population for this study were school teachers who work in Zarqa education districts (9152 teachers) second semester 2016/ 2017. The teachers in the selected schools were invited to participate in the study. Teachers' participation was voluntary, confidential, and anonymous. Teachers completed the 44-item OHI. 900 teachers randomly selected participated in this study. The survey response rate was $98.7 \%$. There were 377 male and 512 female teachers; 397 with BSc, and 492 with graduate degree; 163 with less than 5 years' experience, 365 teachers with 5 to less than 10 years' experience, and 361 teachers with 10 years and more experience. 


\section{Data Collection Instruments}

The data for this investigation were collected using questionnaires: The Personal Resilience Questionnaire (PRQ), and Leadership Practices Inventory (LPI) (Observer), also, demographic information about teachers, such as gender, level of education, and teaching experience were collected.

The first questionnaire, the (PRQ) was developed by Daryl Conner and his associates at ODR, Inc. in 1990 (Conner, 1993). The instrument was used to assess the seven dimensions of resilience: Positive (The World), Positive (Yourself), Focused, Flexible (Thoughts), Flexible (Social), Organized, and Proactive. The 70 questions in the PRQ reflect the resilience dimensions above. The response choices for the 70 items are based on a five-point Likert scale; they are: strongly disagree, disagree, moderate, agree, and strongly agree.

The second questionnaire, The LPI (Observer), was completed by both the teachers to measure the leadership actions and behaviors of their principal. The instrument was developed by Kouzes \& Posner (1987) to empirically measure the leadership actions and behaviors of a leader based on five leadership practices: challenging the process, inspiring a shared vision, enabling others to act, modeling the way, and encouraging the heart. Six statements are used to measure each of these practices using a five-point Likert scale. All statements are ranked as follows: rarely or very seldom; once in a while; sometimes; fairly often; very frequently or almost always, with a higher value representing greater use of the leadership practices. To determine the participant's leadership practice, the value of the items marked for each scale will be totaled. Using the participants' total scores, group mean scores are calculated for each leadership practices (Kouzes \& Posner, 1993).

The total scores were interpreted as following: it should notice that the researcher used the response scale of each item which ranged from 1 to 5 to determine these cut points according to the following manner: $1-2.33=$ low, $2.34-3.67=$ moderate, $3.68-5.00=$ high. The alpha level was set at .05 a priori.

\section{Reliability and Validity}

Reliability of the LPI was determined using test-retest reliability and Cronbach's Coefficient Alpha. Coefficient alphas for each of the five of LPI-Observer was: challenging the process (0.83); inspiring a shared vision (0.85); enabling others to act (0.84); modeling the way (0.84); and encouraging the heart (0.89). In order to assure the psychometric properties of the questionnaire in Jordanian culture, internal consistency measures of reliability were computed for the instrument by calculating Cronbach's alpha coefficients from a pilot study composed of 45 subjects whom were not included in the final study sample. As a result, the internal consistency rating for each subscale was: challenging the process (0.79); inspiring a shared vision (0.81); enabling others to act $(0.83)$; modeling the way $(0.81)$; and encouraging the heart (0.88).

Reliability of the PRQ was determined using test-retest reliability and Cronbach's Coefficient Alpha. However, computed coefficient alphas for each of the seven dimensions of personal resilience questionnaire was: Positive: the world (0.79); Positive: yourself (0.83); focused (0.82); flexible: thoughts (0.81); flexible: social (0.87), organized (0.88), and proactive (0.86). In order to assure the psychometric properties of the questionnaire in Jordanian culture, internal consistency measures of reliability were computed for the instrument by calculating Cronbach's alpha coefficients from a pilot study composed of 45 subjects whom were not included in the final study sample. As a result, the internal consistency rating for each subscale was: Positive: the world (0.77); Positive: yourself (0.81); focused (0.81); flexible: thoughts 
(0.79); flexible: social (0.85), organized (0.86), and proactive (0.84). With its high internal consistency rating, LPI-Observer and PRQ were assumed to be an appropriate instrument for the present research.

\section{RESULTS}

Q1: How do teachers at Zarqa Governorate perceive their principals' leadership practice? Means and standards deviations were used to answer this question. Starting with the means, it is observable from Table 2 that the lowest mean of practicing principals' leadership is (2.92) and the highest mean is (4.39). This result indicated that teachers perceived their principals highly practice Leadership (3.95). With regard to the means and standard deviations of the five dimensions of the LPI Scale, the mean of encouraging the heart is higher than all other means (4.39), followed by enabling others to act (4.12), challenging the process (3.60), modeling the way (3.08), and inspiring a shared vision (2.92) is the lowest mean.

Table 2: Means and standard deviation of dimensions of principals' leadership practice as perceived by their teachers

\begin{tabular}{|l|l|l|}
\hline Dimension & Means & $\begin{array}{l}\text { Standard } \\
\text { deviations }\end{array}$ \\
\hline Challenging the process & 3.60 & 0.92 \\
\hline Inspiring a shared vision & 2.92 & 0.94 \\
\hline Enabling others to act & 4.12 & 0.74 \\
\hline Modeling the way & 3.08 & 0.93 \\
\hline Encouraging the heart & 4.39 & 0.50 \\
\hline LPI overall & 3.95 & 0.19 \\
\hline
\end{tabular}

Q2: How do teachers at Zarqa Governorate perceive their principals' personal resilience? Starting with the means, it is observable from Table 3 that the lowest mean of principals' personal resilience is (3.14) and the highest mean is (4.14). With regard to the means and standard deviations of the seven dimensions of the PRQ Scale, the mean of organized is higher than all other means (4.14), followed by flexible: social (3.86), flexible: thoughts (3.71), proactive (3.68), focused (3.52), positive: the world (3.43), and positive: yourself (3.14).

Table 3: Means and standard deviation of dimensions of principals' Personal Resilience as perceived by their teachers

\begin{tabular}{|l|l|l|}
\hline Personal Resilience Characteristics & Means & $\begin{array}{l}\text { Standard } \\
\text { deviations }\end{array}$ \\
\hline Positive: The World & 3.43 & 0.42 \\
\hline Positive: Yourself & 3.14 & 0.73 \\
\hline Focused & 3.52 & 0.62 \\
\hline Flexible: Thoughts & 3.71 & 0.64 \\
\hline Flexible: Social & 3.86 & 0.611 \\
\hline Organized & 4.14 & 0.48 \\
\hline Proactive & 3.68 & 0.74 \\
\hline
\end{tabular}

Q3: Are there significant relationships among principals' personal resilience and their leadership as perceived their teachers?

Table 4 displays the correlation matrix between resilience dimensions and leadership practices for this investigation. Statistically significant, positive relationships were observed among: Positive: The World with challenging the process $(\mathrm{r}=.278)$, inspiring a shared vision $(\mathrm{r}=.224)$, enabling others to act $(\mathrm{r}=.242)$, modeling the Way $(\mathrm{r}=.225)$, and encouraging the heart (.095). 
Positive: Yourself with challenging the process $(\mathrm{r}=.066)$. Focused with challenging the process $(\mathrm{r}=.084)$, and inspiring a shared vision $(\mathrm{r}=.092)$. Flexible: Thoughts with challenging the process $(\mathrm{r}=.067)$, and inspiring a shared vision $(\mathrm{r}=.074)$. Organized with inspiring a shared vision ( $\mathrm{r}=.071)$, and modeling the way $(\mathrm{r}=.074)$.

Table 4: Correlations Matrix: Pearson Correlations among Personal Resilience Dimensions and Leadership Practices of School Principals as perceived by their teachers.

\begin{tabular}{|l|l|l|l|l|l|}
\hline & $\begin{array}{l}\text { Challenging } \\
\text { the process }\end{array}$ & $\begin{array}{l}\text { Inspiring } \\
\text { a shared } \\
\text { vision }\end{array}$ & $\begin{array}{l}\text { Enabling } \\
\text { others to } \\
\text { act }\end{array}$ & $\begin{array}{l}\text { Modeling } \\
\text { the way }\end{array}$ & $\begin{array}{l}\text { Encouragin } \\
\text { g the heart }\end{array}$ \\
\hline Positive: The World & $.278^{*}$ & $.224^{*}$ & $.242^{*}$ & $.225^{*}$ & $.095^{*}$ \\
\hline Positive: Yourself & $.066^{*}$ & .052 & .044 & .042 & .030 \\
\hline Focused & $.084^{*}$ & $.092^{*}$ & .017 & .017 & .054 \\
\hline Flexible: Thoughts & $.067^{*}$ & $.074^{*}$ & .001 & .008 & .036 \\
\hline Flexible: Social & .040 & .038 & .007 & .008 & .024 \\
\hline Organized & .035 & $.071^{*}$ & .039 & $.074^{*}$ & .026 \\
\hline Proactive & .012 & .008 & .019 & .010 & .008 \\
\hline
\end{tabular}

$* p=0.05$

Q4: Do principals leadership practice differ based on teachers gender, education, and teaching experience?

A Three-Way MANOVA was used to test the teachers perceived the principals leadership practice as related to their gender, education, and teaching experience. The MANOVA results in Table 3 show that there is difference in teachers perceived the principals leadership practice related to their education.

Table 5: Three-Way Multivariate Tests the teachers perceived the principals leadership practice as related to their gender, education, and teaching experience

\begin{tabular}{|l|l|c|c|c|c|c|}
\hline & & Value & $\mathrm{F}$ & $\begin{array}{c}\text { Hypothesis } \\
\mathrm{df}\end{array}$ & Error df & \multicolumn{1}{c|}{ Sig. } \\
\hline Gender & $\begin{array}{l}\text { Hotelling's } \\
\text { Trace }\end{array}$ & .009 & 1.355 & 6.000 & 872.000 & .230 \\
\hline Education & $\begin{array}{l}\text { Hotelling's } \\
\text { Trace }\end{array}$ & .018 & 2.644 & 6.000 & 872.000 & $.015^{*}$ \\
\hline Experience & Wilks' Lambda & .981 & 1.392 & 12.000 & 1744.000 & .162 \\
\hline
\end{tabular}

t-tests were used to examine the difference in means between teachers education (BSc, and Graduate) in each dimension of leadership practice Scale. Table 6 show that there were no significant differences at the 0.05 level between BSc. and Graduate teachers in all dimensions of LPI. There were significant differences at the 0.05 level in LPI overall, the differences were for BSc. Teachers $(M=4.00)$ that mean BSc. teachers perceived principals' leadership practice better than graduate teachers did. 
Table 6: t-test, mean and SD among teachers in each dimension of LPI scale regarding to their education

\begin{tabular}{|c|c|c|c|c|c|c|}
\hline Dependent Variables & Education & Mean & SD & $\mathrm{T}$ & $\mathrm{df}$ & Sig. \\
\hline \multirow[t]{2}{*}{ Challenging the process } & BSc. & 3.60 & .87 & \multirow{2}{*}{$-1.333-$} & \multirow{2}{*}{887} & \multirow{2}{*}{183} \\
\hline & Grad. & 3.68 & .91 & & & \\
\hline \multirow[t]{2}{*}{ Inspiring a shared vision } & BSc. & 2.89 & .90 & \multirow{2}{*}{$-.562-$} & \multirow{2}{*}{887} & \multirow{2}{*}{.574} \\
\hline & Grad. & 2.93 & .96 & & & \\
\hline \multirow[t]{2}{*}{ Enabling others to act } & BSc. & 4.14 & .73 & \multirow{2}{*}{1.175} & \multirow{2}{*}{887} & \multirow{2}{*}{.240} \\
\hline & Grad. & 4.08 & .75 & & & \\
\hline \multirow[t]{2}{*}{ Modeling the way } & BSc. & 3.11 & .93 & \multirow{2}{*}{.742} & \multirow{2}{*}{887} & \multirow{2}{*}{458} \\
\hline & Grad. & 3.06 & .93 & & & \\
\hline \multirow[t]{2}{*}{ Encouraging the heart } & BSc. & 4.40 & .49 & \multirow{2}{*}{.003} & \multirow{2}{*}{887} & \multirow{2}{*}{.998} \\
\hline & Grad. & 4.40 & .51 & & & \\
\hline \multirow[t]{2}{*}{ LPI overall } & BSc. & 4.00 & .00 & \multirow{2}{*}{4.097} & \multirow{2}{*}{887} & \multirow{2}{*}{.000} \\
\hline & Grad. & 3.95 & .19 & & & \\
\hline
\end{tabular}

Q5: Do principals personal resilience differ based on teachers gender, education, and teaching experience?

A Three-Way MANOVA was used to test the teachers perceived the principals resilience as related to their gender, education, and teaching experience. The MANOVA results in Table 7 show that there is no difference in teachers perceived the principals personal resilience related to their gender, education, and teaching experience.

Table 7: Three-Way Multivariate Tests the teachers perceived the principals personal resilience as related to their gender, education, and teaching experience

\begin{tabular}{|l|l|l|l|l|l|c|}
\hline Variables & & Value & F & $\begin{array}{l}\text { Hypothesi } \\
\text { s df }\end{array}$ & Error df & Sig. \\
\hline Gender & Hotelling's Trace & .004 & .533 & 7.0 & 871.0 & .810 \\
\hline Education & Hotelling's Trace & .003 & .434 & 7.0 & 871.0 & .881 \\
\hline Experience & Wilks' Lambda & .985 & .936 & 14.0 & 1742.0 & .519 \\
\hline
\end{tabular}

\section{CONCLUSIONS AND DISCUSSIONS}

Based on the research questions, the following conclusions can be drawn as a result of this investigation: (a) The resilient dimension of Positive (the World) was correlated with the five leadership practices of challenging the process, inspiring a shared vision, enabling others to act, modeling the way and encouraging the heart of school principals. Thus, principals who are more Positive (the world) are better able to challenge the process, inspire a shared vision, enable others to act, model the way and encourage the heart. According to Conner's model (1993), positive (the World) resilient people: Focus on positive view of environment, see environment as complex and challenging, see opportunities and possibilities Thus, the researcher concluded from this investigation that principals who are more Positive (the World) are better able to inspire a shared vision and enable others to act in to strengthen their leadership abilities. (b) The resilient dimension of Focused was correlated with challenging the process, and inspiring a shared vision. According to Conner's model (1993), focused people: Strongly committed to goals, find meaning or purpose in life, have a sense of purpose and priorities, have clarity of purpose, have a sense of direction in life. Thus, the researcher concluded from this investigation that principals who are more focused are better able to challenging the process, and inspire a shared vision to strengthen their leadership abilities. (c) The resilient dimension of Flexible (thoughts) was correlated with challenging the process, and inspiring a shared vision. According to Conner's model (1993), Flexible (thoughts) resilient 
people: Cope with ambiguity comfortably, willing to look at situations from multiple points of view and suspend judgment, open-minded, creative in finding effective ways to achieve goals. Thus, the researcher concluded from this investigation that principals who are more Flexible (thoughts) are better able to challenge the process and inspire a shared vision to strengthen their leadership abilities. (d) The resilience dimension of Organized was correlated with the leadership practices of inspiring a shared vision, and modeling the way. Thus, principals who are more organized are better able to inspire a shared vision, and model the way. According to Conner's model (1993), organized resilient people: Find order in chaos and structure in ambiguity, have the discipline to assess the available information, and plan the steps accordingly, create a workable detailed plan, systematically and in a sequence.

A number of studies have found one or more of these characteristic associated with resilience (Conner, 1993; Hagevick, 1998; Benard, 1993). The leadership practice of challenging the process requires the principal to have the ability to create order during conditions of uncertainty. Principals should be able to master change during uncertainty, and take action to lead their people through these unstable times. While principals must act decisively under uncertain conditions, they must also be cognizant of the fear and doubt that teachers and students feel when faced with the unknown (Kouzes \& Posner, 1995, 2002).

The leadership practice of inspiring a shared vision helps principals to maintain a vision because there are a lot of distractions and ambiguity that cause teachers and students to misunderstand the goals and values of the school. The Kouzes and Posner (2002) research found that when leaders clearly articulated their vision for the organization, constituents indicated significantly higher levels of organizational productivity.

The leadership practice of enabling others to act offers steps that the principal can take to foster collaboration to create positive interactions among all their constituents (teachers, students, parents, and community). With a trusting relationship and through face-to-face interactions, the principal connects teachers and students to the right sources of influence and information. By sharing information, he or she creates a climate of trust and collaboration that is critical to the success of the school. When teachers access and share information, they become more involved in the decision making process, which significantly improve the quality of their services (Kouzes \& Posner, 2002)

The leadership practice of modeling the way implies that the principal takes every opportunity to show teachers, staff, students, parents and the community by their own example that they are deeply committed to the values and aspirations of the school. Therefore, it is important that the principal maintains direct contact with his or her teachers, students, staff, parents and the community. To keep teachers and students focused on the meaning and significance of the vision, the principal should implement things in small, planned increments (Kouzes \& Posner, 1995, 2002).

The leadership practice of encouraging the heart implies that the principal gives recognition to those contributing to the success of the project, and encouraging teachers, staff and students by celebrating team accomplishment regularly. It is important that the principals should look for opportunities to celebrate accomplishments. Teachers, staff, and students often need encouragement and motivation to achieve the goals set by the school (Kouzes \& Posner, 2002).

The results of this investigation have implications for researchers and practioners in education responsible for developing and maintaining strategies to achieve the goal of principals effectively serving as school leaders. These findings can serve as a basis for school principals to 
assess their leadership strengths and weaknesses and use the findings toward the improvement of leadership performance.

According to Conner (1993), principals should continuously look for ways to help their teachers and students understand the dynamics of change and what they can do to manage the change process. Kouzes and Posner (2002) maintained that school principals must be agents of change. The quest for change is an adventure that tests the skills and abilities of school leaders. Also, they should actually initiate change and assume the risk for a new enterprise. Principals who accept the resilience model reflect greater change adaptability. Resilient principals who manage change successfully not only improve their school's performance but also become more effective leaders. Principals who have the leadership abilities reflected in the resilience dimensions and the leadership practices will be better able to bring meaningful structure and discipline to a changing world.

\section{References}

Abu-Tineh, A., Khasawneh, S., \& Al-Omari, A. (2008). Kouzes and Posner's transformational leadership model in practice: The case of Jordanian schools. Leadership \& Organization Development Journal, 29(8), 648-660.

Benard, B. (1993). Fostering resiliency in kids. Educational Leadership, 51(3), 44-48.

Bolman, L.G. \& Deal, T.E. (1997). Reframing organizations: Artistry, choice, and leadership (2nd Ed.). San Francisco: Jossey-Bass Publishers.

Conner, D. R. (1993). Managing at the speed of change: How resilient managers succeed and prosper where others fail. NY: Villard Books.

Cunningham, W.G., \& Cordeiro, P.A. (2000). Educational administration: A problem - based approach. Boston: Allyn and Bacon.

Du Brain, A. J. (1998). Leadership: Research findings, practice, and skills. Boston: Houghton Mifflin Company.

Flach F. (1988). Resilience: Discovering a new strength at times of stress. NY: Fawcett Columbine.

Garmezy, N. \& Masten, A. S. (1986). Stress, competence, and resilience: Common frontiers for therapist and psychopathologist. Behavior Therapy, 17(5), 500 - 521.

Greenfield, W. D. (1995). Toward a theory of school administration: The centrality of leadership. Educational Administration Quarterly, 31 (1), 61 - 80.

Hagevik, S. (1998). Resilience required. Journal of Environmental Health,.60, 10, 37.

Henderson, N., \& Milstein, M.M. (1996). Resiliency in schools: Making it happens for students and educators. Thousand Oaks, CA: Corwin Press.

Higgins, G.O. (1994). Resilient adults: Overcoming a cruel past. San Francisco: Jossey-Bass, Inc.

Jones, P. S. (1991). Adaptability: a personal resource for health. Scholarly inquiry for nursing practice, 5(2), 95-108.

Kouzes, J. M. \& Posner, B. Z. (1987). The Leadership challenge: How to get extraordinary things done in organizations. San Francisco: Jossey - Bass Publishers.

Kouzes, J. M. \& Posner, B.Z. (1993). Leadership practices inventory. A self-assessment and analysis (expanded edition). San Francisco: Jossey - Bass Inc., Publishers.

Kouzes, J. M. \& Posner, B. Z. (1995). The leadership challenge. How to keep getting extraordinary things done in organizations (2nd Ed.). Jossey-Bass publishers: San Francisco.

Kouzes, J. M., \& Posner, B. J. (2002). Leadership challenge (3rd Ed.). San Francisco: Jossey-Bass.

Osburn, F. W. (1993). Principal perceptions of rewards and organizational characteristics as incentives to assume leadership in school improvement. Doctoral dissertation, Florida State University, 1993).Dissertation Abstracts International, 54, 02A.

Patterson, J. (2001). Resiliency in the face of adversity. The School Administrator. Available from the American Association of School Administrators, Virginia. Retrieved from Http:// www.aasa.org

Sagor, R. (1996). Building resiliency in students. Educational Leadership, 54, 38-43. 
Senge, P., Cambron-McCabe, N., Lucas, T., Smith, B., Dutton, J., \& Kleiner, A. (2000). Schools that learn: A fifth discipline fieldbook for educators, parents, and everyone who cares about education. NY: Doubleday.

Tirozzi, G. N. (2001). The artistry of leadership. The evolving role of the secondary school principal. Phi Delta Kappan, 86, 6, 438-439.

Wang, C.W. \& Gordon, E.W. (Ed.) (1994). Educational resilience in Inner City America: Challenges and prospects. NJ: Lawrence Erlbaum Associates, Inc.

Webster, E.W. (1988). The high - performing educational manager. In Readings on

Leadership in Education. From the Archives of Phi Delta Kappa International (2000).

Werner, E. E. \& Smith, R.S. (2001). Journeys from childhood to midlife: Risk resilience, and recovery. NY: Cornell University Press.

Whitake, T., \& Turner, E. (2000). What is your priority? Bulletin, 84, 16.

Wolin, S.J. \& Wolin, S. (1993). The Resilient Self: How survivors of troubled families rise above adversity. NY: Villard Books.

\section{PERSONAL RESILIENCE QUESTIONNAIRE (PRQ)}

Strongly Disagree $=1$, Disagree $=2$, Slightly Disagree $/$ Agree $=3$, Agree $=4$, Strongly Agree $=5$

1. Task that don't have a simple or clear - cut solution are fun.

2. I like myself.

3. Stressful situations are no time for joking.

4. I am committed to getting what I want out of life.

5. If a day starts out badly, things will probably be bad all day.

6. I am comfortable in a variety of social situations.

7. Questions that don't have a right answer are really frustrating.

8. It's easy for me to become depressed and unexcited about things.

9. I feel at ease fairly quickly with most people.

10. If I read, I tend to stick to favorite magazines or familiar authors.

11. If you want to be happy, you will be happy.

12. There are people in my life who sometimes turn to me for support and advice.

13. People find me cheerful and happy.

14. I prefer to stick to tried and true clothing styles.

15. I am willing to take a few risks to get what I want.

16. I have a lot of confidence in myself.

17. I usually wake up in the morning excited about what the day will bring.

18. I can solve any problems I am faced with.

19. I have one or more very close friends who I can tell my private thoughts to.

20. I use lists a lot to remind me of all the little things that need to be done.

21 . When times are rough, I focus my attention on a brighter tomorrow.

22. I am a creative person.

23. One thing I am really good at is making sense out of confusing situations.

24. I am happiest when I've established a predictable routing in my life.

25. Other people see me as an optimist.

26. I don't feel comfortable sharing my most private thoughts with anyone.

27. I can think down the road five years and picture what I will be doing.

28. I feel anxious when I 'm with people I don't know well.

29 . I try not to rely on others for anything; self - sufficiency is my goal.

30. In my work and home, everything has a place and everything is in its place.

31. I don't understand people who make jokes about serious issues.

32. I am often reluctant to ask others for help in a difficult situation. 
33. I am always trying to learn new things or find ways to improve myself.

34. My life is a mess right now and I don't know which direction to head.

35. I hate to make schedules and then have to stick to them.

36. I prefer things that are symmetrical - that is, completely balanced.

37. My life has no direction or purpose.

38. I feel alone in the world.

39. I feel good about the things I have done with my life so far.

40. I 'm good at coming up with clever solutions to fix machinery, resolve conflicts, or mend other things that aren't working right.

41. I don't manage time well - it's always slipping away from me.

42. If I had a big, messy stack of papers in front of me, I am confident that I could organize them into some sensible system.

43. I maintain my focus on achieving my goals even when there are obstacles in my path.

44. It's possible for me to turn off troublesome thoughts; once I get a negative idea in my head, I can't think about anything else.

45. I feel confused and indecisive when trying to make important decisions in my life.

46. When I'm going somewhere, I sometimes will take a different route or path just to see what's there.

47. When I picture my "ideal self," I'd have to say that the way I really am is not very much like it.

48. When a crisis occurs in my life, I can keep my focus and get myself back on track.

49. When I am around other people, I am often the one who starts things happening.

50. Sometimes one new piece of information will completely change how I see a situation.

51. My friends would gladly help with my transportation or offer a place for me to stay if I ever needed it.

52. I have lost out on opportunities because I couldn't make up my mind about what I wanted.

53. My achievements so far have been a result of hard work and discipline.

54. The things I am doing in my life right now are an expression of my personal goals and aims.

55. I don't have a clear sense of what my skills and abilities are.

56. I prefer to try new restaurants and unusual dishes when I eat out.

57. I think more often about the things that can go wrong in the world that I do about the things that can go right.

58. You should always make a detailed plan before trying to overcome a complex problem.

59. I'm not capable enough to do the things I like to do.

60. I am able to focus my attention on what I'm doing without getting sidetracked easily.

61. Challenging myself to do something extremely difficult seems like a waste of energy.

62. I am powerless to change the things in my life I don't like.

63. I have a system for organizing the clothes in my closet that I could explain to someone else.

64. Traveling to a country where I don't know the language really doesn't sound good to me.

65. When it comes to resisting temptation (for example, a dieter resisting a delicious, rich dessert), I have a great deal of willpower.

66. I prefer to know exactly what I'm supposed to do rather than figure it out as I go along.

67. I often jump from one project to another rather than finish one all the way through.

68. When everything is going well for me, I worry because I know that something bad is bound to happen.

69. Other people are better at thinking of creative ways to get things done that I am.

70. I am currently working on several projects that I am very committed to.

\section{LEADERSHIP PRACTICE INVENTORY (LPI) (OBSERVER)}

If you rarely or very seldom do what is described in the statement, "1."

If you do what is described once in a while, "2." 
If you sometimes do what is described, "3."

If you do what is described fairly often, "4."

If you do what is described very frequently or almost always, "5."

\section{5}

1. I seek out challenging opportunities that test my skills and abilities.

2. I describe to others the kind of future I would like for us to create together.

3. I involve others in planning the actions we will take.

4. I am clear about my own philosophy of leadership.

5. I take the time to celebrate accomplishments when project milestones are reached.

6. I stay up-to-date on the most recent developments affecting our organization.

7. I appeal to others to share my dream of the future as their own.

8. I treat others with dignity and respect.

9. I make certain that the projects I lead are broken down into manageable steps.

10. I make sure that people are recognized for their contributions to the success of our projects.

11. I challenge the way we do things at work.

12. I clearly communicate a positive and hopeful outlook for the future of our organization.

13. I give people a lot of discretion to make their own decisions.

14. I spend time and energy making certain that people adhere to the values that have been agreed on.

15. I praise people for a job well done.

16. I look for innovative ways we can improve what we do in this organization.

17. I show others how their long-term future interests can be realized by enlisting in a common vision.

18. I develop cooperative relationships with the people I work with.

19. I let others know my beliefs on how to best run the organization I lead.

20. I give the members of the team lots of appreciation and support for their contributions.

21. I ask "What can we learn?" when things do not go as expected.

22. I look ahead and forecast what I expect the future to be like.

23. I create an atmosphere of mutual trust in the projects I lead.

24. I am consistent in practicing the values I espouse.

25. I find ways to celebrate accomplishments.

26. I experiment and take risks with new approaches to my work even when there is a chance of failure.

27. I am contagiously excited and enthusiastic about future possibilities.

28. I get others to feel a sense of ownership for the projects they work on.

29. I make sure the work group sets clear goals makes plans, and establishes milestones for the projects I lead.

30. I make it a point to tell the rest of the organization about the good work done by my organization. 